\title{
Red-light absorption and fluorescence of phytochrome chromophores: a comparative theoretical study
}

Olle Falklöf and Bo Durbeej

\section{Linköping University Post Print}

\section{Tweet}

N.B.: When citing this work, cite the original article.

Original Publication:

Olle Falklöf and Bo Durbeej, Red-light absorption and fluorescence of phytochrome chromophores: a comparative theoretical study, 2013, Chemical Physics, (425), 19-28.

http://dx.doi.org/10.1016/j.chemphys.2013.07.018

Copyright: Elsevier

http://www.elsevier.com/

Postprint available at: Linköping University Electronic Press

http://urn.kb.se/resolve?urn=urn:nbn:se:liu:diva-96694 


\title{
Red-light absorption and fluorescence of phytochrome chromophores: A comparative theoretical study
}

\author{
Olle Falklöf and Bo Durbeej*
}

Division of Computational Physics, IFM, Linköping University, SE-581 83 Linköping, Sweden

* Corresponding author. E-mail address: bodur@ifm.liu.se (B. Durbeej)

Tel: +46-(0)13-282497

Fax: +46-(0)13-137568 


\begin{abstract}
Currently, much experimental effort is being invested in the engineering of phytochromes, a large superfamily of photoreceptor proteins, into fluorescent proteins suitable for bioimaging in the near-infrared regime. In this work, we gain insight into the potential of computational methods to contribute to this development by investigating how well representative quantum chemical methods reproduce recently recorded red-light absorption and emission maxima of synthetic derivatives of the bilin chromophores of phytochromes. Focusing on the performance of time-dependent density functional theory but using also the ab initio CIS(D), CC2 and CASPT2 methods, we explore how various methodological considerations influence computed spectra and find, somewhat surprisingly, that density functionals lacking exact exchange reproduce the experimental measurements with smaller errors than functionals that include exact exchange. Thus, for the important class of chromophores that bilins constitute, the widely established trend that hybrid functionals give more accurate excitation energies than pure functionals does not apply.
\end{abstract}

\title{
Keywords
}

bilin chromophores, photoreceptor proteins, fluorescent proteins, excited states, quantum chemistry 


\section{Graphical abstract}

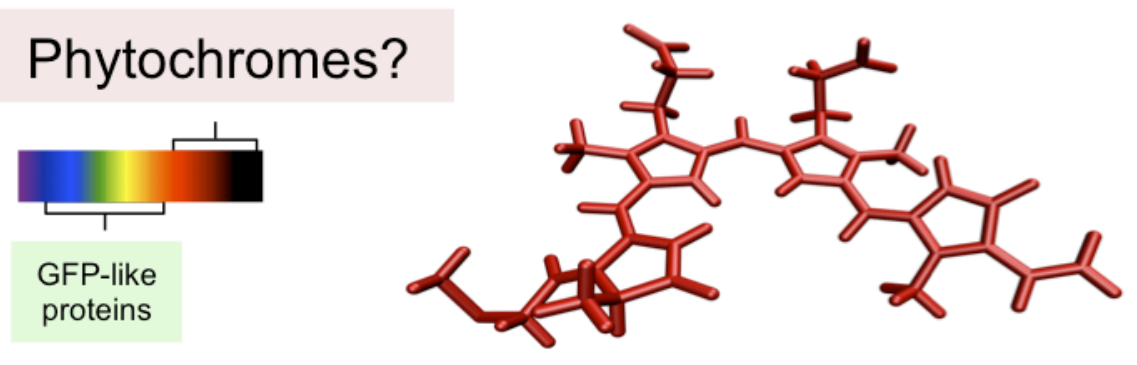

\section{Highlights}

- Calculation of red-light absorption and emission of phytochrome chromophores

- Comparison of TD-DFT and ab initio methods

- Pure functionals show better accuracy than hybrid functionals 


\section{Introduction}

The use of genetically encodable fluorescent proteins as molecular imaging tools in biology remains a rapidly evolving field where the paradigm-shifting green fluorescent protein (GFP) from jellyfish [1,2] has now been accompanied by systems that emit light in most regions of the visible spectrum $[3,4]$. To expand the range of possible applications of these tools, however, one area of particular current interest is the engineering of fluorescent proteins with absorption and emission maxima in the nearinfrared window between 650 and $900 \mathrm{~nm}$ [5], which is not easily attained by GFP-like proteins [4]. At such wavelengths, mammalian tissue is more transparent [6] and therefore better amenable to the monitoring of processes like tumor growth and metastasis [7]. Along those lines, a number of near-infrared fluorescent proteins [8-10] have recently been engineered not from GFP-like proteins, but from phytochromes [11] that constitute a large superfamily [12] of red and far-red-absorbing photoreceptor proteins that bind a linear tetrapyrrole (bilin) chromophore. Indeed, using bacteriophytochromes as templates, which is advantageous in that the biliverdin IX $\alpha$ (BV) chromophore of bacteriophytochromes occurs naturally in mammalian tissue, fluorescent proteins with absorption and emission maxima in the 684-701 and 708-719 $\mathrm{nm}$ ranges have been reported [8-10].

As demonstrated by previous studies [13-15], computational methods can contribute to the design of fluorescent proteins in a number of different ways, such as help identifying factors that influence key properties [3,4] like absorption and emission wavelengths, extinction coefficients, fluorescence quantum yields, brightness (fluorescence quantum yield $\times$ extinction coefficient) and photostabilities. For example, in order for phytochrome-derived fluorescent proteins to find widespread use as imaging tools, an understanding is needed of how the $<0.10$ fluorescence quantum yields of the aforementioned systems engineered from bacteriophytochromes [8-10] can be improved. The relatively low fluorescence quantum yields of these systems reflect that phytochromes, being photoreceptor proteins that switch between inactive red-absorbing (Pr) and active far-red-absorbing (Pfr) forms [16,17], have evolved [18] to rather 
maximize their quantum yields for the chromophore photoisomerization that triggers the conversion of Pr into Pfr [19-24].

In this work, we take advantage of current advances in synthetic bilin chemistry [25] and present a theoretical study that provides valuable insight into the applicability of computational methods in the development of improved fluorescent proteins based on phytochromes. Specifically, we present a systematic investigation of how well different density functional theory (DFT) and ab initio quantum chemical methods reproduce the unique set of experimental absorption and emission maxima of free bilin chromophores in solution recently recorded by Zienicke et al. [25]. These authors were able to overcome the difficulty in measuring the weak fluorescence of bilins [26] by synthesizing sterically locked chromophores in which the competing photoisomerization of the $\mathrm{C} 15=\mathrm{C} 16$ bond is hindered (see Fig. 1).

Although a few quantum chemical studies of the UV-vis spectroscopy of bilin chromophores have previously been reported [27-30], in the (at the time) absence of experimental fluorescence data these mostly focused on absorption features, and also did not extensively compare the performance of different methods. Thus, the present study helps filling an important gap in the existing literature. Furthermore, whereas the previous calculations used experimental spectra of chromophore-protein complexes as reference data $[27,29,30]$, this work uses spectra devoid of any influence from the protein, which allows for a more direct assessment of the quantum chemical accuracy. Besides being relevant for the further development of phytochrome-derived fluorescent proteins [8-10], the results of this investigation will also be valuable for computational studies addressing photochemical problems in phytochrome research in their own right, of which deciphering the chromophore photoisomerization mechanism is of particular interest [31-35].

Finally, it should be emphasized that this study is not concerned with reporting calculations for assessing the applicability of excited-state quantum chemical methods to as wide a range of molecules as possible. Rather, we have chosen to focus on a single class of molecules of broad chemical interest, and to invest all computational efforts in exploring, quite comprehensively, how various methodological considerations influence computed absorption and emission maxima of these particular compounds alone. As 
such, our work is similar in scope to recent quantum chemical benchmark investigations focusing exclusively on the chromophore of GFP [36,37], the original tool for molecular imaging in biology. Given the potential of phytochrome-derived systems to enable new applications of fluorescent proteins and the positive implications that the reported data will have for basic phytochrome research, conducting a study along those lines seems worthwhile.

\section{Computational details}

In the experimental reference study [25], five different locked bilin chromophores with either one (between rings $\mathrm{C}$ and $\mathrm{D}$ ) or two (between both rings $\mathrm{C}$ and $\mathrm{D}$ and rings $\mathrm{A}$ and B) cyclic locks were considered. Furthermore, the absorption and fluorescence measurements were done at both $\mathrm{p} H=1$ and $\mathrm{p} H=7.8$ [25]. However, in order to avoid any ambiguity as to the protonation states of the chromophores, this work focuses exclusively on the $\mathrm{pH}=1$ measurements, which pertain to fully protonated species with net charges of +1 . This is also the protonation state in Pr and Pfr phytochromes [38,39]. For the locked bilin denoted $15 E a$, the difference between the absorption and excitation maxima at $\mathrm{p} H=1$ is quite large, $0.11 \mathrm{eV}$ [25]. For this reason, this compound was not included in the present calculations. For the other four bilins denoted 5Za15Ea, 5Ea15Ea, $5 Z s 15 Z a$ and $15 Z a$, the absorption and excitation maxima deviate no more than $0.01 \mathrm{eV}$ from each other. These molecules are shown in Fig. 2 and are the ones studied in this work, except that hydrogen atoms were used in place of the $\mathrm{C} 8$ and $\mathrm{C} 12$ propionic carboxyl groups. In earlier computational studies, these substitutions have been shown to have a minor influence on both the electronic and geometric features of bilin chromophores $[33,40]$.

Importantly, Fig. 2 displays the chromophores in the actual stereoisomeric forms considered in the calculations, with methine bridges between rings not subjected to a cyclic lock throughout adopting a $Z s$ geometry. This choice is motivated by the experimental observation that ordinary bilins prefer a closed $Z s Z s Z s$ conformation in solution [16]. Furthermore, although the unlocked BC bridge of 5Za15Ea, 5Ea15Ea, $5 Z s 15 Z a$ allows these chromophores to adopt four different conformations (Zs, Za, Es 
and $E a$ ) with respect to the $\mathrm{BC}$ bridge, and the unlocked $\mathrm{AB}$ and $\mathrm{BC}$ bridges of $15 \mathrm{Za}$ similarly give rise to 16 possible conformations, a previous theoretical study has confirmed that a solution environment favors the stereoisomers shown in Fig. 2 over the alternative ones [41]. This was found to hold true for both cationic and neutral chromophore species [41], suggesting that the preference of ordinary bilins to adopt a closed conformation in solution [16] extends also to the acidic aqueous solution [25] that this work pertains to. Overall, then, we have not felt the need to explore the conformational preference of the present chromophores by means of, e.g., classical molecular dynamics simulations, which would require a suitable set of non-standard force-field parameters to be derived.

Ground $\left(\mathrm{S}_{0}\right)$ and excited-state $\left(\mathrm{S}_{1}\right.$, the lowest excited singlet state from which the fluorescence occurs and which dominates the red-absorbing $\mathrm{Q}$ band) geometries of the chromophores were first optimized with the B3LYP hybrid density functional in combination with the SVP basis set, using a time-dependent DFT (TD-DFT) formalism [42-44] for the excited-state optimizations. Both sets of geometries were optimized both in the gas phase and with the integral equation formulation of the polarizable continuum model (PCM) [45] to describe solvent effects [25]. To roughly assess whether the use of an implicit-solvation model of this type is appropriate, the PCM optimizations were for some of the chromphores ( $5 Z a 15 E a, 5 Z s 15 Z a$ and $15 Z a)$ also done in the presence of a few explicit water molecules, as shown in Fig. 3. To explore basis-set effects on the resulting structures, in turn, the gas-phase optimizations were also carried out with three alternative basis sets (all of which are larger than SVP): TZVP, cc-pVDZ and aug-ccpVDZ.

With optimized ground and excited-state structures in hand, obtained in different environments and with different basis sets, absorption and emission maxima were first calculated using TD-DFT at the B3LYP-PCM/cc-pVDZ level of theory. The absorption maxima were computed as vertical $\mathrm{S}_{0} \rightarrow \mathrm{S}_{1}$ excitation energies on ground-state geometries, and the emission maxima as vertical $\mathrm{S}_{1} \rightarrow \mathrm{S}_{0}$ emission energies on excitedstate geometries. For both absorption and emission, solvent effects on the TD-DFT energies were included by means of a state-specific (SS) PCM approach [46,47], which for a polar solvent like water is expected to be more accurate than using the conventional 
linear response (LR) approach [48]. For the sake of comparison, however, absorption maxima were also computed with LR solvation. While the calculation of absorption maxima were done in the non-equilibrium (NEQ) regime where it is assumed that only the solvent electronic ("fast") degrees of freedom have time to respond to the change in chromophore electron density upon excitation, the calculation of emission maxima were performed in the equilibrium (EQ) regime where also the solvent nuclear ("slow") degrees of freedom are equilibrated. This approach accounts for the fact that the geometric excited-state relaxation preceding the emission is a slower process than the initial excitation.

From an analysis that we will return to below of how the environment (gas phase, PCM, or PCM + explicit water molecules) and choice of basis set (SVP, TZVP, ccpVDZ, or aug-cc-pVDZ) for the B3LYP geometry optimizations affect the absorption and emission maxima resulting from the singlepoint calculations just described, the PCM geometries optimized without explicit water molecules and the SVP basis set were then used to obtain further estimates of the spectroscopic parameters by carrying out additional TD-DFT-PCM singlepoint calculations with a set of complimentary density functionals. This set included both a variety of standard functionals based on the generalized gradient approximation (GGA) and functionals [49-52] applicable also in the event that the excited states in question exhibit charge-transfer character, which pose a considerable challenge for standard functionals [43,53]: BP86, BLYP, PBE (GGAs), $\tau$ HCTH (a meta-GGA), BHHLYP, PBE0 (hybrid GGAs), M06-2X, M06-HF (hybrid meta-GGAs), LC-BLYP, LC- $\omega$ PBE, CAM-B3LYP and $\omega$ B97X-D (long-range-corrected hybrid GGAs). These calculations were done with three different basis sets: cc-pVDZ, cc-pVTZ and 6-31+G(d,p).

Since the B3LYP/SVP excited-state geometry optimization of the $5 E a 15 E a$ chromophore with PCM failed to converge because of root flipping, the emission maximum of this system was instead estimated by performing calculations at the B3LYP/SVP excited-state geometry optimized in the gas phase, and adding to the resulting energies a correction term to account for the error so introduced. Motivated by the observation in Table 1 (see below) that the PCM-induced spectral shift is of similar magnitude for absorption and emission, the correction term was assigned a value $(+0.06$ 
$\mathrm{eV}$ ) equaling the shift in absorption caused by the PCM-induced change in ground-state geometry of the 5Ea15Ea chromophore.

Although we believe that the favorable cost-performance ratio of TD-DFT is likely to render it the preferred choice of methodology for future computational studies along the lines outlined in the introduction, it is clearly also of interest to assess the performance of alternative excited-state methods that rather include electron correlation effects in an ab initio fashion. To this end, absorption and emission maxima were also computed using on the one hand configuration interaction singles (CIS) with perturbation-theory treatment of doubles corrections (CIS(D)) [54] and approximate coupled-cluster singles and doubles (CC2) [55], which are among the least costly of such methods, and on the other complete active space second-order perturbation theory (CASPT2) [56], which also includes static correlation and is widely regarded as one of the most accurate approaches in the field. These calculations were carried out with the ccpVDZ basis set.

The CASPT2 calculations were done in a state-specific fashion on top of two-root $\left(\mathrm{S}_{0}, \mathrm{~S}_{1}\right)$ state-average CASSCF wavefunctions, with active spaces comprising 14 electrons distributed over $14 \pi$-orbitals (14e/14o), and with a real level shift of 0.2 Hartree. The corresponding oscillator strengths were computed from CASSCF wavefunctions using the CASSCF state interaction method [57]. Ideally, CASSCF-based treatment of conjugated molecules should include the full $\pi$-system in the active space. However, since this is not feasible for the present chromophores, the active space was for each molecule reduced to a more manageable $14 \mathrm{e} / 14 \mathrm{o}$ by, following the guidelines of Veryazov et al. [58], selecting the $\pi$-orbitals that a preceding Hartree-Fock calculation placed closest in energy to the highest occupied and lowest unoccupied $\pi$-orbitals.

Up until this point, all spectroscopic parameters had been calculated based on B3LYP-derived geometries. To explore how this (standard) choice of method for geometry optimization influences the results, the absorption and emission maxima of the $5 Z a 15 E a$ chromophore were also calculated based on ground and excited-state geometries optimized with the full range of density functionals used for singlepoint calculations, as specified above. 
All calculations were done with the GAUSSIAN 09 [59], TURBOMOLE 6.3 $[60,61]$ and MOLCAS 7.8 [62-64] programs. TURBOMOLE 6.3 was used for geometry optimizations with the TZVP, cc-pVDZ and aug-cc-pVDZ basis sets, and for CIS(D) and CC2 calculations with the RICC2 module [65]. MOLCAS 7.8 was used for CASPT2 calculations. GAUSSIAN 09 was used for all other calculations.

\section{Results and discussion}

\subsection{Influence on spectroscopic parameters: Molecular geometries in different environments}

In this section, we will briefly outline some results that guided the execution of the calculations to be presented in the subsequent sections, particularly with respect to choosing the environment in which the molecular geometries are most appropriately optimized. Since the aim is more to illustrate how this choice affects the computed transition energies than to validate a specific choice in terms of its accuracy, no comparison will be made with experimental data in this section.

First, we consider the B3LYP-PCM/cc-pVDZ absorption and emission maxima of the locked bilin chromophores given in Table 1, which were obtained using B3LYP/SVP geometries optimized in three different environments: in the gas phase, with PCM, and with PCM and explicit water molecules. Accordingly, it can be seen that gas-phase geometries yield absorption maxima whose deviations from the absorption maxima based on PCM geometries range from $0.04 \mathrm{eV}$ (the $5 Z s 15 Z a$ chromophore) to a more substantial $0.13 \mathrm{eV}(15 \mathrm{Za})$, and that the corresponding differences with respect to emission maxima reach an even greater magnitude of $0.17 \mathrm{eV}(15 Z a)$. As for also including a few water molecules in the geometry optimizations, the resulting absorption and emission maxima lie consistently within $0.02 \mathrm{eV}$ from those obtained with the "PCM-only" geometries. Based on these findings, it was decided to use geometries optimized with PCM (but without water molecules) for all subsequent calculations. The differences in gas-phase and PCM bond lengths are highlighted in Table S1 of the Supplementary Data (SD) and correspond, for all chromophores and for both states $\left(\mathrm{S}_{0}\right.$ 
and $\mathrm{S}_{1}$ ) in question, to root-mean square deviations of about $0.01 \AA$ and maximum absolute deviations of about $0.02-0.03 \AA$.

Second, we turn to the B3LYP-PCM/cc-pVDZ absorption and emission maxima given in Tables S2 and S3 of the SD, which were calculated on B3LYP geometries reoptimized with larger basis sets than SVP. For the sake of computational efficiency, these optimizations were performed in the gas-phase, thus assuming transferability of the observed basis-set effects to the solution environment. From the calculations, it is found that none of the ways to improve the basis set - changing from double- $\zeta$ to triple- $\zeta$ quality (TZVP), using a correlation-consistent scheme (cc-pVDZ), or including diffuse functions (aug-cc-pVDZ) - changes the geometries to such an extent that the computed transition energies are notably affected. Indeed, for all chromophores the absorption and emission maxima vary no more than $0.02-0.07 \mathrm{eV}$ with the choice of basis set for the geometry optimizations. Based on these results, all subsequent calculations were carried out using geometries optimized with the SVP basis set.

\subsection{Influence on spectroscopic parameters: TD-DFT calculations with different functionals}

The Q-band absorption and emission maxima computed with TD-DFT are summarized in Tables 2 (5Za15Ea and $5 E a 15 E a)$ and $3(5 Z s 15 Z a$ and $15 Z a)$. While these calculations were done with the double- $\zeta$ cc-pVDZ basis set, the results from complementary calculations with alternative basis sets are given in Tables S4, S5 and S6 of the SD. For all methods, cc-pVDZ yields spectroscopic parameters in close agreement $(<0.02 \mathrm{eV})$ with those obtained with the alternative basis sets. For this reason, we will here focus exclusively on the cc-pVDZ data.

Before discussing these results, however, it should be noted that the procedure to estimate absorption maxima as vertical $\mathrm{S}_{0} \rightarrow \mathrm{S}_{1}$ excitation energies (and hence emission maxima as vertical $S_{1} \rightarrow S_{0}$ emission energies) was, in a number of cases, validated by also computing the full UV-vis spectra by convoluting several tens of transitions with Gaussian functions of fixed full width at half maximum (set to the standard value of 0.5 $\mathrm{eV}$ [66]). Thereby, in support of the current procedure, the differences between the 
Gaussian-convoluted Q-band absorption maxima and the corresponding $\mathrm{S}_{0} \rightarrow \mathrm{S}_{1}$ excitation energies were found to be very small $(<0.02 \mathrm{eV})$.

Focusing initially on the calculations with solvent effects included in a SS fashion [46,47], using NEQ solvation for absorption and EQ solvation for emission, it is notable from Tables 2 and 3 that all density functionals give results that, without exception, are blue-shifted relative to the experimental absorption and emission maxima [25]. Overall, for all four chromophores the closest agreement with these values is achieved by the pure GGAs (BP86, BLYP, PBE and $\tau-\mathrm{HCTH}$ ), which deviate by $\sim 0.15 \mathrm{eV}$. Among the exactexchange-containing hybrid functionals, the best performers are those that include the smallest fractions of exact exchange - B3LYP (20\%) and PBE0 (25\%) - which reproduce absorption maxima with an accuracy of $\sim 0.3 \mathrm{eV}$ and emission maxima with an accuracy of $\sim 0.2 \mathrm{eV}$ (note that experimental emission maxima are not available for the $5 Z s 15 Z a$ and $15 Z a$ chromophores).

Comparing hybrids belonging to the same family of functionals, B3LYP is 0.09-0.18 eV more accurate than BHHLYP (50\%), and M06-2X (54\%) is $0.02-0.08 \mathrm{eV}$ more accurate than M06-HF (100\%). That hybrid functionals tend to overestimate the energies of singlet excited states of organic molecules, and increasingly so with the amount of exact exchange, has been established in one of the most extensive TD-DFT benchmark studies reported to date [67]. However, while the present results are consistent with this finding, the better accuracy here achieved by the pure GGAs than by B3LYP and PBE0 contrasts with the average performances documented in that study. Indeed, among the plethora of functionals considered, it was found that the best performance is shown by hybrids containing around $20 \%$ of exact exchange, and that pure GGAs typically red-shift excitation energies by $\sim 0.3 \mathrm{eV}$ [67]. Thus, the surprising finding that, for the present systems, pure GGAs come closest to experimental data appears to be due to cancellation of errors. At the same time, although there are many potential sources for such an effect, further calculations to be discussed below seem to indicate that two of the more straightforwardly implicated ones - molecular geometries and treatment of solvent effects - are not at play here. 
Continuing with the long-range-corrected hybrids (LC-BLYP, LC- $\omega$ PBE, CAMB3LYP and $\omega$ B97X-D), which differ from the "global" hybrids by using a growing fraction of exact exchange as the interelectronic distance increases [49,50,52], these blueshift the absorption and emission maxima by $\sim 0.4-0.5$ and $\sim 0.3 \mathrm{eV}$, respectively. That the long-range-corrected hybrids for these particular systems are less accurate than the best-performing global hybrids may be testament to the character of the $S_{1}$ states, them being singly excited HOMO $\rightarrow$ LUMO $\pi \pi^{*}$ valence states with similar charge distributions between the pyrrole rings as the corresponding ground states. For such states, there is no need to increase the amount of exact exchange at large interelectronic distances, as is the case for charge-transfer states [43]. Data illustrating the singleexcitation HOMO $\rightarrow$ LUMO character of the $\mathrm{S}_{1}$ states are provided in Tables S7, S8 and S9 of the SD.

Besides accuracy in computed absorption and emission maxima, it is also informative to evaluate how well the various functionals reproduce the difference between these two observables - the Stokes shift. Experimentally, the Q bands of the $5 Z a 15 E a$ and $5 E a 15 E a$ chromophores exhibit small Stokes shifts in the 0.04-0.07 eV range [25]. From Table 2, it can be seen that also for the Stokes shifts are the best performers the pure GGAs (Stokes shifts in the $0.07-0.10 \mathrm{eV}$ range), followed by B3LYP and PBE0 in one range $(0.12-0.16 \mathrm{eV})$, and the remaining hybrids and long-rangecorrected hybrids in another $(0.18-0.25 \mathrm{eV})$. Despite their overall inferiority to B3LYP and PBE0 for TD-DFT applications [67], these results lend further credence to the use of pure GGAs for computational studies of bilin chromophores. Of course, the close numerical agreement with the experimental Stokes shifts shown by the pure GGAs is largely a consequence of a fortuitous cancellation of errors. For all four chromophores, the variation in the computed Stokes shifts reflects that the absorption maxima are more sensitive to the choice of functional than the emission maxima. Indeed, as detailed in Tables 2 and 3, the corresponding standard deviations amount to 0.13-0.15 (SS NEQ absorption maxima) and 0.08-0.09 eV (SS EQ emission maxima).

To investigate whether the tendency of the calculations to overestimate the Stokes shifts is mostly due to the intrinsic performance of the methods, or if the dielectric- 
continuum description of the solvent is a contributing factor, the absorption and emission maxima of the $5 Z a 15 E a$ and $5 E a 15 E a$ chromophores were also computed in the gas phase, but with all other technical details unaltered. Thereby, it was found that the Stokes shifts resulting from these calculations (not shown) fall in ranges similar to the aforementioned, PCM-derived Stokes shifts: 0.05-0.08 (pure GGAs), 0.09-0.13 (B3LYP and PBE0) and 0.14-0.21 eV (other hybrids and long-range-corrected hybrids). Hence, the overestimation of the Stokes shifts seems to be mostly of quantum chemical origin.

Another valuable piece of information on the performance of TD-DFT for bilin chromophores can be obtained by analyzing how well the calculations reproduce the experimental differences in absorption maximum between the molecules, which is done in Table S10 of the SD. In part, these differences can be explained by the number of conjugated double bonds in the respective molecule, which is 11 for $5 Z a 15 E a$ and $5 E a 15 E a$, and 12 for $5 Z s 15 Z a$ and $15 Z a$. Consequently, the latter molecules absorb at longer wavelengths, and the ability of computational methods to accurately quantify such shifts is a particularly pertinent test of their potential to contribute to the design of phytochrome-derived fluorescent proteins. Continuing to focus on the calculations with solvent effects included in a SS fashion [46,47], Table S10 shows that all density functionals reproduce correctly the trend whereby the absorption of the $15 \mathrm{Za}, 5 \mathrm{Za} 15 \mathrm{Ea}$ and $5 E a 15 E a$ chromophores is incrementally blue-shifted relative to that of the longestwavelength-absorbing $5 Z s 15 Z a$ reference species. Furthermore, even quantitatively, all methods perform well, yielding shifts of 0.01-0.03 (15Za), 0.11-0.13 (5Za15Ea) and 0.13-0.16 eV (5Ea15Ea) that closely match the corresponding experimental shifts of $0.07,0.13$ and $0.17 \mathrm{eV}$, respectively [25].

Up until this point, the discussion has been concerned with calculations where solvent effects on the TD-DFT energies are included by means of a SS approach. For a polar solvent like water, this is expected to be more accurate than using the conventional LR approach [46,47]. In this light, it is interesting to note from Tables 2 and 3 that the two schemes give quite different estimates of the absorption maxima of the locked bilin chromophores. In fact, for each chromophore and for every density functional, the LR value is red-shifted relative to the SS value by $0.14-0.20 \mathrm{eV}$. Accordingly, for these particular systems, the best agreement with experimental data is actually achieved by the 
LR approach, at least as far as absorption maxima are concerned. While it would have been interesting to further compare the two schemes by testing how well the LR approach performs also for emission maxima, this option was not pursued, partly because the experimental reference values are fewer for emission than for absorption, and partly because the main focus of our study is to assess the relative merits of different excitedstate methods. Since there seems to be no reason to believe that the "better" performance of the LR approach for absorption maxima rests on physically motivated grounds [46,47], we will, unless otherwise noted, continue to focus the discussion on calculations performed with SS solvation.

\subsection{Influence on spectroscopic parameters: Ab initio calculations}

The ab initio calculations are summarized in Table 4. As expected, CIS blue-shifts the spectroscopic parameters; absorption maxima by $\sim 0.8-0.9 \mathrm{eV}$ and emission maxima by $\sim 0.6-0.7 \mathrm{eV}$. However, adding perturbative doubles corrections to the CIS energies reduces the blue shifts to $\sim 0.3-0.4$ and $\sim 0.2 \mathrm{eV}$, respectively. Thus, CIS(D) is of similar accuracy as B3LYP and PBE0. CC2, in turn, gives absorption and emission maxima that are $\sim 0.05 \mathrm{eV}$ closer to the experimental values than the CIS(D) ones. Overall, then, in the absence of high-level ab initio excited-state methods readily applicable to bilin chromophores, the data in Table 4 support the use of TD-DFT for photochemical modeling of these systems. This notion is further corroborated by the fact that the 0.04-0.07 eV Stokes shifts of the 5Za15Ea and 5Ea15Ea chromophores are more pronouncedly overestimated by CIS $(0.24-0.28 \mathrm{eV}), \mathrm{CIS}(\mathrm{D})(0.20-0.21 \mathrm{eV})$ and CC2 $(0.17-0.18 \mathrm{eV})$, than by many of the density functionals. At the same time, it should be noted that the absorption and emission maxima obtained with CIS(D) and CC2 do not account for solvent effects at the corresponding levels of theory but using CIS, whereby the comparison with TD-DFT is not altogether balanced and the potential of these methods perhaps not fully realized.

As for the CASPT2 results, it is notable that these are further from the experimental values than the CIS(D) and CC2 results, especially in light of the many examples in the literature where CASPT2 performs very well for conjugated molecules 
[68] and the fact that none of the typical pitfalls - such as the intruder state problem [69] and improper mixing of valence and Rydberg excited states [70] - manifested itself in the calculations. Despite the absence of such effects, the necessity to employ a suboptimal (here 14e/14o) active space and the choice to use the cc-pVDZ basis set (rather than an extended basis set that would better capture correlation effects) are likely to impact negatively on the accuracy of the CASPT2 results. Furthermore, there is also the uncertainty whether SS solvation should be preferred over LR solvation, because with the latter approach the CASPT2 absorption maxima actually show excellent agreement with the experimental data. At any rate, since the aim of the CASPT2 calculations was not to obtain the best possible ab initio estimates of the spectroscopic parameters, but to assess whether the inclusion of double-excitation effects in the theoretical treatment is warranted, efforts to improve these calculations were not prioritized. As can be seen from the CI coefficients and natural-orbital occupation numbers in Table S9, the CASSCF wavefunctions underlying the CASPT2 calculations clearly suggest that such effects are of minor importance for the $\mathrm{S}_{1}$ states.

3.4. Influence on spectroscopic parameters: Molecular geometries by different density functionals

So far, all spectroscopic parameters have been calculated based on molecular structures optimized with B3LYP, which is a standard approach in contemporary quantum chemistry, at least as far as electronic ground states are concerned. Nonetheless, considering for example the observation in a related study that excitation energies of the conjugated retinal chromophore utilized by rhodopsin photoreceptors vary substantially with the bond lengths [71], it is of interest to assess how the use of other density functionals for the ground and excited-state geometry optimizations influences the results. To this end, the absorption and emission maxima of the $5 Z a 15 E a$ chromophore were also calculated based on geometries optimized with the full set of functionals used for TD-DFT singlepoint calculations. These results are presented in Table 5, and details (bond lengths) of the resulting geometries are collected in Table S11 of the SD. 
A number of conclusions can be drawn from the data in Table 5. First, absorption maxima are more sensitive than emission maxima to the choice of functional for the geometry optimizations, which parallels the observation made earlier with regard to the TD-DFT singlepoint calculations. In fact, for every functional, the absorption shift between the B3LYP ground-state geometry and the ground-state geometry obtained with that particular functional, is larger than the emission shift between the corresponding excited-state geometries. This effect is reflected in the standard deviations, which naturally increase when each calculation is performed at a unique geometry, but increase more pronouncedly for absorption $(0.13 / 0.14 \rightarrow 0.23 \mathrm{eV})$ than for emission $(0.08 \rightarrow 0.12$ $\mathrm{eV})$.

Second, while using a pure GGA (BP86, BLYP, PBE and $\tau$-HCTH) instead of B3LYP for the geometry optimizations does not impact negatively on the accuracy of the spectroscopic parameters, choosing a global hybrid that contains a larger fraction of exact exchange (BHHLYP, M06-2X and M06-HF) increases the blue shift relative to the experimental absorption maximum by $\sim 0.1-0.2 \mathrm{eV}$. The same goes for the long-rangecorrected hybrids (LC-BLYP, CAM-B3LYP and wB97X-D), which have been demonstrated to sometimes experience problems in simultaneously offering an accurate description of both ground-state properties and excitation energies [72]. Thus, having already noted that they compare favorably with B3LYP and PBE0 in estimating absorption and emission maxima for a common set of B3LYP geometries, pure GGAs seem well-suited for applications to bilin chromophores also in terms of the ground and excited-state equilibrium structures they produce.

\subsection{Influence on spectroscopic parameters: Possible sources for cancellation of errors}

The results in Table 5 seem to eliminate the possibility that the better agreement with experimental spectroscopic parameters achieved by pure GGAs (Tables 2 and 3 ) is due to a fortuitous cancellation of "method" errors in these functionals by errors in molecular structure. Indeed, for the pure GGAs, the variation in spectroscopic parameters with respect to molecular structure is not of a magnitude $(\leq 0.06 \mathrm{eV})$ that this scenario appears likely. Another scenario is that the method errors are cancelled by the errors attributable 
to the PCM treatment of the water solvent. To investigate this possibility, absorption maxima of the locked bilin chromophores were also calculated in the gas phase. These calculations are presented in Table 6 , along with the corresponding solvatochromic shifts relative to the gas phase.

Two key observations can be made from Table 6. First, the variation in solvatochromic shifts between the DFT methods is notably smaller than the variation in gas-phase absorption maxima. This indicates that it is largely intrinsic method features that dictate how well a given functional fares compared to other functionals, and that the better performance of the pure GGAs is not an artifact from the way the solvent is treated. Specifically, taking the $5 Z a 15 E a$ chromophore as an example, the variation in gas-phase absorption maxima between the DFT methods amounts to $0.28 \mathrm{eV}$ (from 2.03 to $2.31 \mathrm{eV}$ ), whereas the estimates of the solvatochromic shifts differ no more than 0.07 (LR NEQ solvation) and $0.09 \mathrm{eV}$ (SS NEQ solvation) from one another. Second, albeit of no consequence for the present discussion, the LR approach favors a distinct red shift that contrasts with the rather negligible shifts predicted by the SS approach.

From the foregoing analysis, we believe that one can disregard the possibility that cancellation of errors originating in molecular structure or treatment of solvent effects plays a decisive role for the observation that pure GGAs reproduce the experimental absorption and emission maxima of the locked bilin chromophores more accurately than what global and long-range-corrected hybrid functionals do. This adds support to our thesis that TD-DFT studies of bilin chromophores may favorably employ pure GGAs, rather than functionals that for a wider spectrum of molecules are known to be more accurate [67].

\section{Conclusions}

In summary, with the overall aim to assess the accuracy of quantum chemical methods for studies of an important group of chromophores underlying the basic photochemistry of phytochromes and highly relevant for the engineering of near-infrared fluorescent proteins [5], we have investigated how well representative methods reproduce the unique set of Q-band absorption and emission maxima of sterically locked synthetic derivatives 
of the BV chromophore that Zienicke et al. recently were able to record in aqueous solution [25]. Focusing primarily on the performance of TD-DFT with a range of different density functionals but considering also the ab initio CIS(D), CC2 and CASPT2 methods, and using a PCM description of the solvent, the following conclusions are arrived at.

First, exploring how sensitive computed absorption and emission maxima are to the environment (gas phase, PCM, or PCM with a few explicit water molecules) in which the ground and excited-state geometry optimizations are performed, it is found that the standard procedure comprising structural relaxation in the gas phase followed by singlepoint calculations with PCM produces spectroscopic parameters that in some cases deviate substantially - by up to 0.13 (absorption) and $0.17 \mathrm{eV}$ (emission) - from those obtained by employing PCM also for structural relaxation. Based on this finding, and the further result that including a few explicit water molecules in the geometry optimizations has a marginal effect in this regard, all subsequent calculations made use of PCM geometries.

Second, as for the performance of TD-DFT, it is found that all density functionals blue-shift the spectroscopic parameters relative to the experimental values, but that the closest agreement $(\sim 0.15 \mathrm{eV})$ with these is achieved by pure GGAs (BP86, BLYP, PBE and $\tau$-HCTH). Thus, the general trend that hybrid functionals containing around $20 \%$ of exact exchange, such as B3LYP and PBE0, offer the overall best description of singlet excited states of organic molecules [67] does not apply to bilin chromophores. However, among the global hybrids considered (BHHLYP, B3LYP, PBE0, M06-2X and M06-HF), the best performance is indeed shown by B3LYP and PBE0, which blue-shift absorption and emission maxima by $\sim 0.3$ and $\sim 0.2 \mathrm{eV}$, respectively. The long-range-corrected hybrids (LC-BLYP, LC- $\omega$ PBE, CAM-B3LYP and $\omega$ B97X-D), in turn, are off by $\sim 0.4-0.5$ and $\sim 0.3 \mathrm{eV}$. Besides providing more accurate transition energies, pure GGAs also yield better estimates of the Stokes shifts. Specifically, with reference to the 0.04-0.07 eV Stokes shifts observed experimentally for the 5Za15Ea and 5Ea15Ea chromophores [25], all functionals overestimate these shifts, but the pure GGAs (shifts of $0.07-0.10 \mathrm{eV})$ less so than B3LYP and PBE0 $(0.12-0.16 \mathrm{eV})$, as well as than the other global hybrids and the long-range-corrected hybrids $(0.18-0.25 \mathrm{eV})$. 
Third, testing the performance of CIS(D) and CC2, which are among the least expensive ab initio procedures for including electron correlation effects in excited states, it is found that these methods are of similar accuracy as B3LYP and PBE0.

Fourth, having exclusively computed spectroscopic parameters based on B3LYP structures of the chromophores, it is observed from complementary calculations on the $5 Z a 15 E a$ species using ground and excited-state structures optimized with all of the current density functionals, that absorption maxima vary to a greater extent with molecular geometry than emission maxima. Moreover, while the agreement with the experimental absorption maximum is worsened by $\sim 0.1-0.2 \mathrm{eV}$ by carrying out geometry optimizations with a long-range-corrected hybrid or a global hybrid that includes more exact exchange than B3LYP, using a pure GGA leaves both absorption and emission maxima largely unchanged.

In closing, then, the overall conclusion of this work is that TD-DFT with pure GGAs is a particularly viable choice of methodology for calculating absorption and emission maxima of bilin chromophores, despite the fact that hybrid functionals typically offer better accuracy for TD-DFT studies [67]. This conclusion, which is strengthened by complementary calculations indicating that the evaluation of the relative performances of the methods is not biased by cancellation of errors, suggests that quantum chemical modeling by pure GGAs holds promise for contributing to the development of nearinfrared fluorescent proteins based on phytochromes, and for shedding new light on key photochemical problems in phytochrome research. Of course, to obtain a fuller picture of the adequacy of TD-DFT/GGA for these tasks, it will also be of interest to assess how well such methodology can be integrated in hybrid quantum mechanics/molecular mechanics schemes for studying phytochrome proteins in their entirety, and applies at non-equilibrium chromophore geometries. Recently, we have taken a first step in this direction [73].

\section{Acknowledgements}


B.D. gratefully acknowledges funding from Linköping University, the Swedish Research Council, the Olle Engkvist Foundation and the Wenner-Gren Foundations, and grants of computing time from the National Supercomputer Centre (NSC) in Linköping.

\section{Appendix A. Supplementary data}

Supplementary data associated with this article can be found in the online version. 


\section{References}

[1] M. Chalfie, Y. Tu, G. Euskirchen, W.W. Ward, D.C. Prasher, Science 263 (1994) 802.

[2] R.Y. Tsien, Annu. Rev. Biochem. 67 (1998) 509.

[3] N.C. Shaner, P.A. Steinbach, R.Y. Tsien, Nat. Methods 2 (2005) 905.

[4] R.H. Newman, M.D. Fosbrink, J. Zhang, Chem. Rev. 111 (2011) 3614.

[5] D. Shcherbo, I.I. Shemiakina, A.V. Ryabova, K.E. Luker, B.T. Schmidt, E.A. Souslova, T.V. Gorodnicheva, L. Strukova, K.M. Shidlovskiy, O.V. Britanova, A.G. Zaraisky, K.A. Lukyanov, V.B. Loschenov, G.D. Luker, D.M. Chudakov, Nat. Methods 7 (2010) 827.

[6] F.F. Jöbsis, Science 198 (1977) 1264.

[7] R.M. Hoffman, Nat. Rev. Cancer 5 (2005) 796.

[8] X. Shu, A. Royant, M.Z. Lin, T.A. Aguilera, V. Lev-Ram, P.A. Steinbach, R.Y. Tsien, Science 324 (2009) 804.

[9] G.S. Filonov, K.D. Piatkevich, L.-M. Ting, J. Zhang, K. Kim, V.V. Verkhusha, Nat. Biotechnol. 29 (2011) 757.

[10] M.E. Auldridge, K.A. Satyshur, D.M. Anstrom, K.T. Forest, J. Biol. Chem. 287 (2012) 7000 .

[11] A.J. Fischer, J.C. Lagarias, Proc. Natl. Acad. Sci. U.S.A. 101 (2004) 17334.

[12] B. Karniol, J.R. Wagner, J.M. Walker, R.D. Vierstra, Biochem. J. 392 (2005) 103.

[13] A.A. Voityuk, M.-E. Michel-Beyerle, N. Rösch, Chem. Phys. 231 (1998) 13.

[14] L.V. Schäfer, G. Groenhof, A.R. Klingen, G.M. Ullmann, M. Boggio-Pasqua, M.A. Robb, H. Grubmüller, Angew. Chem. Int. Ed. 46 (2007) 530.

[15] C. Filippi, F. Buda, L. Guidoni, A. Sinicropi, J. Chem. Theory Comput. 8 (2012) 112.

[16] N.C. Rockwell, Y.-S. Su, J.C. Lagarias, Annu. Rev. Plant Biol. 57 (2006) 837.

[17] N.C. Rockwell, J.C. Lagarias, ChemPhysChem 11 (2010) 1172.

[18] K.C. Toh, E.A. Stojković, I.H.M. van Stokkum, K. Moffat, J.T.M. Kennis, Proc. Natl. Acad. Sci. U.S.A. 107 (2010) 9170.

[19] J.C. Lagarias, H. Rapoport, J. Am. Chem. Soc. 102 (1980) 4821. 
[20] F. Andel III, J.C. Lagarias, R.A. Mathies, Biochemistry 35 (1996) 15997.

[21] C. Kneip, P. Hildebrandt, W. Schlamann, S.E. Braslavsky, F. Mark, K. Schaffner, Biochemistry 38 (1999) 15185.

[22] J.R. Wagner, J.S. Brunzelle, K.T. Forest, R.D. Vierstra, Nature 438 (2005) 325.

[23] K. Inomata, M.A.S. Hammam, H. Kinoshita, Y. Murata, H. Khawn, S. Noack, N. Michael, T. Lamparter, J. Biol. Chem. 280 (2005) 24491.

[24] T. Rohmer, C. Lang, J. Hughes, L.-O. Essen, W. Gärtner, J. Matysik, Proc. Natl. Acad. Sci. U.S.A. 105 (2008) 15229.

[25] B. Zienicke, L.-Y. Chen, H. Khawn, M.A.S. Hammam, H. Kinoshita, J. Reichert, A.S. Ulrich, K. Inomata, T. Lamparter, J. Biol. Chem. 286 (2011) 1103.

[26] H. Al-Ekabi, I.-M. Tegmo-Larson, S.E. Braslavsky, A.R. Holzwarth, K. Schaffner, Photochem. Photobiol. 44 (1986) 433.

[27] J.-Y. Hasegawa, M. Isshiki, K. Fujimoto, H. Nakatsuji, Chem. Phys. Lett. 410 (2005) 90 .

[28] A.H. Göller, D. Strehlow, G. Hermann, ChemPhysChem 6 (2005) 1259.

[29] O.A. Borg, B. Durbeej, J. Phys. Chem. B 111 (2007) 11554.

[30] R.A. Matute, R. Contreras, L. González, J. Phys. Chem. Lett. 1 (2010) 796.

[31] J. Dasgupta, R.R. Frontiera, K.C. Taylor, J.C. Lagarias, R.A. Mathies, Proc. Natl. Acad. Sci. U.S.A. 106 (2009) 1784.

[32] P. Altoè, T. Climent, G.C. De Fusco, M. Stenta, A. Bottani, L. Serrano-Andrés, M. Merchán, G. Orlandi, M. Garavelli, J. Phys. Chem. B 113 (2009) 15067.

[33] A. Strambi, B. Durbeej, Photochem. Photobiol. Sci. 10 (2011) 569.

[34] Y. Yang, M. Linke, T. von Haimberger, J. Hahn, R. Matute, L. González, P. Schmieder, K. Heyne, J. Am. Chem. Soc. 134 (2012) 1408.

[35] B. Durbeej, Phys. Chem. Chem. Phys. 11 (2009) 1354.

[36] C. Filippi, M. Zaccheddu, F. Buda, J. Chem. Theory Comput. 5 (2009) 2074.

[37] N.H. List, J.M. Olsen, T. Rocha-Rinza, O. Christiansen, J. Kongsted, Int. J. Quantum Chem. 112 (2012) 789.

[38] B. Borucki, D. von Stetten, S. Seibeck, T. Lamparter, N. Michael, M.A. Mroginski, H. Otto, D.H. Murgida, M.P. Heyn, P. Hildebrandt, J. Biol. Chem. 280 (2005) 34358. 
[39] T. Rohmer, H. Strauss, J. Hughes, H. de Groot, W. Gärtner, P. Schmieder, J. Matysik, J. Phys. Chem. B 110 (2006) 20580.

[40] B. Durbeej, L.A. Eriksson, Phys. Chem. Chem. Phys. 8 (2006) 4053.

[41] O.A. Borg, B. Durbeej, Phys. Chem. Chem. Phys. 10 (2008) 2528.

[42] F. Furche, R. Ahlrichs, J. Chem. Phys. 117 (2002) 7433.

[43] A. Dreuw, M. Head-Gordon, Chem. Rev. 105 (2005) 4009.

[44] G. Scalmani, M.J. Frisch, B. Mennucci, J. Tomasi, R. Cammi, V. Barone, J. Chem. Phys. 124 (2006) 094107.

[45] E. Cancès, B. Mennucci, J. Tomasi, J. Chem. Phys. 107 (1997) 3032.

[46] R. Improta, V. Barone, G. Scalmani, M.J. Frisch, J. Chem. Phys. 125 (2006) 054103.

[47] R. Improta, G. Scalmani, M.J. Frisch, V. Barone, J. Chem. Phys. 127 (2007) 074504.

[48] M. Cossi, V. Barone, J. Chem. Phys. 115 (2001) 4708.

[49] T. Yanai, D.P. Tew, N.C. Handy, Chem. Phys. Lett. 393 (2004) 51.

[50] O.A. Vydrov, G.E. Scuseria, J. Chem. Phys. 125 (2006) 234109.

[51] Y. Zhao, D.G. Truhlar, Theor. Chem. Acc. 120 (2008) 215.

[52] J.-D. Chai, M. Head-Gordon, Phys. Chem. Chem. Phys. 10 (2008) 6615.

[53] D.J. Tozer, R.D. Amos, N.C. Handy, B.O. Roos, L. Serrano-Andrés, Mol. Phys. 97 (1999) 859.

[54] M. Head-Gordon, R.J. Rico, M. Oumi, T.J. Lee, Chem. Phys. Lett. 219 (1994) 21.

[55] O. Christiansen, H. Koch, P. Jørgensen, Chem. Phys. Lett. 243 (1995) 409.

[56] K. Andersson, P.-Å. Malmqvist, B.O. Roos, J. Chem. Phys. 96 (1992) 1218.

[57] P.-Å. Malmqvist, B.O. Roos, Chem. Phys. Lett. 155 (1989) 189.

[58] V. Veryazov, P.-Å. Malmqvist, B.O. Roos, Int. J. Quantum Chem. 111 (2011) 3329.

[59] M.J. Frisch, G.W. Trucks, H.B. Schlegel, G.E. Scuseria, M.A. Robb, J.R. Cheeseman, G. Scalmani, V. Barone, B. Mennucci, G.A. Petersson, H. Nakatsuji, M. Caricato, X. Li, H.P. Hratchian, A.F. Izmaylov, J. Bloino, G. Zheng, J.L. Sonnenberg, M. Hada, M. Ehara, K. Toyota, R. Fukuda, J. Hasegawa, M. Ishida, T. Nakajima, Y. Honda, O. Kitao, H. Nakai, T. Vreven, J.A. Montgomery, Jr., J.E. Peralta, F. Ogliaro, M. Bearpark, J.J. Heyd, E. Brothers, K.N. Kudin, V.N. Staroverov, R. Kobayashi, J. Normand, K. Raghavachari, A. Rendell, J.C. Burant, S.S. Iyengar, J. Tomasi, M. Cossi, N. Rega, J.M. Millam, M. Klene, J.E. Knox, J.B. Cross, V. Bakken, C. Adamo, J. 
Jaramillo, R. Gomperts, R.E. Stratmann, O. Yazyev, A.J. Austin, R. Cammi, C. Pomelli, J.W. Ochterski, R.L. Martin, K. Morokuma, V.G. Zakrzewski, G.A. Voth, P. Salvador, J.J. Dannenberg, S. Dapprich, A.D. Daniels, Ö. Farkas, J.B. Foresman, J.V. Ortiz, J. Cioslowski, D.J. Fox, GAUSSIAN 09, Revision B.01, Gaussian Inc., Wallingford, CT, 2009.

[60] R. Ahlrichs, M. Bär, M. Häser, H. Horn, C. Kölmel, Chem. Phys. Lett. 162 (1989) 165.

[61] TURBOMOLE V6.3 2011, a development of University of Karlsruhe and Forschungszentrum Karlsruhe GmbH, 1989-2007, TURBOMOLE GmbH, since 2007; available at: http://www.turbomole.com (accessed May 13, 2013).

[62] G. Karlström, R. Lindh, P.-Å. Malmqvist, B.O. Roos, U. Ryde, V. Veryazov, P.-O. Widmark, M. Cossi, B. Schimmelpfennig, P. Neogrády, L. Seijo, Comput. Mater. Sci. 28 (2003) 222.

[63] V. Veryazov, P.-O. Widmark, L. Serrano-Andrés, R. Lindh, B.O. Roos, Int. J. Quantum Chem. 100 (2004) 626.

[64] F. Aquilante, L. De Vico, N. Ferré, G. Ghigo, P.-Å. Malmqvist, P. Neogrády, T.B. Pedersen, M. Pitoňák, M. Reiher, B.O. Roos, L. Serrano-Andrés, M. Urban, V. Veryazov, R. Lindh, J. Comput. Chem. 31 (2010) 224.

[65] C. Hättig, F. Weigend, J. Chem. Phys. 113 (2000) 5154.

[66] É.A.G. Brémond, J. Kieffer, C. Adamo, J. Mol. Struct. (THEOCHEM) 914 (2009) 3. [67] D. Jacquemin, V. Wathelet, E.A. Perpète, C. Adamo, J. Chem. Theory Comput. 5 (2009) 2420.

[68] B.O. Roos, K. Andersson, M.P. Fülscher, P.-Å. Malmqvist, L. Serrano-Andrés, K. Pierloot, M. Merchán, in: I. Prigogine, S.A. Rice (Eds.), Advances in Chemical Physics, Vol. 93: New Methods in Computational Quantum Mechanics, Wiley, New York, 1994, p. 219.

[69] B.O. Roos, K. Andersson, M.P. Fülscher, L. Serrano-Andrés, K. Pierloot, M. Merchán, V. Molina, J. Mol. Struct. (THEOCHEM) 388 (1996) 257.

[70] L. Serrano-Andrés, M. Merchán, I. Nebot-Gil, R. Lindh, B.O. Roos, J. Chem. Phys. 98 (1993) 3151. 
[71] M. Wanko, M. Hoffmann, P. Strodel, A. Koslowski, W. Thiel, F. Neese, T. Frauenheim, M. Elstner, J. Phys. Chem. B 109 (2005) 3606.

[72] M.A. Rohrdanz, J.M. Herbert, J. Chem. Phys. 129 (2008) 034107.

[73] O. Falklöf, B. Durbeej, J. Comput. Chem. 34 (2013) 1363. 
Table 1

B3LYP Q-band absorption and emission maxima at geometries optimized in the gas phase and in aqueous solution (in $\mathrm{eV}$ ). ${ }^{\mathrm{a}}$

\begin{tabular}{llcc}
\hline & & Absorption $^{\mathrm{b}}$ & Emission $^{\mathrm{c}}$ \\
Chromophore & Geometry $^{\mathrm{d}}$ & $\Delta E\left(\mathrm{~S}_{0} \rightarrow \mathrm{S}_{1}\right)$ & $\Delta E\left(\mathrm{~S}_{1} \rightarrow \mathrm{S}_{0}\right)$ \\
\hline $5 Z a 15 E a$ & Gas phase & $2.12(1.75)$ & $1.97(1.51)$ \\
& PCM & $2.19(1.91)$ & $2.05(1.94)$ \\
& PCM + explicit $\mathrm{H}_{2} \mathrm{O}$ & $2.19(1.92)$ & $2.03(1.95)$ \\
$5 E a 15 E a$ & Gas phase & $2.15(1.66)$ & $2.03(1.59)$ \\
& PCM & $2.21(1.87)$ & $-^{\mathrm{e}}$ \\
$5 Z s 15 Z a$ & Gas phase & $2.04(1.29)$ & $-^{\mathrm{e}}$ \\
& PCM & $2.08(1.34)$ & $1.91(1.25)$ \\
& PCM + explicit $\mathrm{H}_{2} \mathrm{O}$ & $2.07(1.34)$ & $1.89(1.26)$ \\
$15 Z a$ & & $1.96(0.72)$ & $1.73(0.51)$ \\
& Gas phase & $2.09(1.21)$ & $1.90(1.02)$ \\
& PCM & $2.07(1.24)$ & $1.92(1.19)$ \\
\hline
\end{tabular}

${ }^{a}$ All transition energies calculated using the cc-pVDZ basis set and PCM.

Oscillator strengths in parentheses.

${ }^{\mathrm{b}}$ Calculated using SS NEQ solvation.

${ }^{\mathrm{c}}$ Calculated using SS EQ solvation.

${ }^{\mathrm{d}}$ Geometry optimized using B3LYP/SVP in either the gas phase, with PCM, or with PCM and explicit water molecules as shown in Fig. 3.

${ }^{\mathrm{e}}$ Excited-state geometry optimization failed to converge because of root flipping. 
Table 2

TD-DFT Q-band absorption and emission maxima of the $5 Z a 15 E a$ and $5 E a 15 E a$ chromophores (in eV). ${ }^{\text {a }}$

\begin{tabular}{|c|c|c|c|c|}
\hline \multirow[b]{3}{*}{ Chromophore } & \multirow[b]{3}{*}{ Functional } & \multicolumn{2}{|c|}{ Absorption } & \multirow{3}{*}{$\begin{array}{c}\frac{\text { Emission }^{\mathrm{b}}}{\text { SS EQ solvation }} \\
\Delta E\left(\mathrm{~S}_{1} \rightarrow \mathrm{S}_{0}\right)\end{array}$} \\
\hline & & LR NEQ solvation & SS NEQ solvation & \\
\hline & & $\Delta E\left(\mathrm{~S}_{0} \rightarrow \mathrm{S}_{1}\right)$ & $\Delta E\left(\mathrm{~S}_{0} \rightarrow \mathrm{S}_{1}\right)$ & \\
\hline \multirow[t]{15}{*}{$5 Z a 15 E a$} & BP86 & $1.89(1.87)$ & $2.05(1.66)$ & $1.96(1.75)$ \\
\hline & BLYP & $1.88(1.86)$ & $2.05(1.66)$ & $1.95(1.75)$ \\
\hline & PBE & $1.89(1.86)$ & $2.05(1.65)$ & $1.96(1.74)$ \\
\hline & $\tau$-HCTH & $1.89(1.89)$ & $2.06(1.70)$ & $1.97(1.78)$ \\
\hline & BHHLYP & $2.17(2.25)$ & $2.36(2.12)$ & $2.15(2.13)$ \\
\hline & B3LYP & $2.01(2.05)$ & $2.19(1.91)$ & $2.05(1.94)$ \\
\hline & PBE0 & $2.05(2.10)$ & $2.23(1.96)$ & $2.07(1.99)$ \\
\hline & M06-2X & $2.12(2.15)$ & $2.31(2.02)$ & $2.11(2.04)$ \\
\hline & M06-HF & $2.19(2.18)$ & $2.38(2.06)$ & $2.13(2.08)$ \\
\hline & LC-BLYP & $2.19(2.23)$ & $2.39(2.12)$ & $2.14(2.14)$ \\
\hline & $L C-\omega P B E^{c}$ & $2.18(2.21)$ & - & - \\
\hline & CAM-B3LYP & $2.13(2.17)$ & $2.31(2.04)$ & $2.11(2.06)$ \\
\hline & $\omega B 97 X-D$ & $2.14(2.18)$ & $2.33(2.05)$ & $2.11(2.06)$ \\
\hline & $\sigma$ (functional $^{\mathrm{d}}$ & 0.13 & 0.14 & 0.08 \\
\hline & $\operatorname{Exp}^{\mathrm{e}}$ & \multicolumn{2}{|c|}{1.89} & 1.85 \\
\hline \multirow[t]{15}{*}{$5 E a 15 E a$} & BP86 & $1.90(1.83)$ & $2.07(1.67)$ & 1.99 \\
\hline & BLYP & $1.89(1.82)$ & $2.06(1.66)$ & 1.99 \\
\hline & PBE & $1.90(1.83)$ & $2.07(1.67)$ & 1.99 \\
\hline & $\tau$-НСТН & $1.90(1.84)$ & $2.07(1.69)$ & 2.00 \\
\hline & BHHLYP & $2.20(2.21)$ & $2.39(2.09)$ & 2.21 \\
\hline & B3LYP & $2.04(2.01)$ & $2.21(1.87)$ & 2.09 \\
\hline & PBE0 & $2.07(2.06)$ & $2.25(1.92)$ & 2.12 \\
\hline & M06-2X & $2.15(2.12)$ & $2.34(2.00)$ & 2.16 \\
\hline & M06-HF & $2.23(2.15)$ & $2.42(2.04)$ & 2.19 \\
\hline & LC-BLYP & $2.24(2.20)$ & $2.43(2.10)$ & 2.20 \\
\hline & $L C-\omega P B E^{c}$ & $2.22(2.18)$ & - & - \\
\hline & CAM-B3LYP & $2.16(2.14)$ & $2.35(2.02)$ & 2.16 \\
\hline & $\omega B 97 X-D$ & $2.18(2.15)$ & $2.36(2.03)$ & 2.17 \\
\hline & $\sigma$ (functional $)^{\mathrm{d}}$ & 0.14 & 0.15 & 0.09 \\
\hline & $\operatorname{Exp}^{\mathrm{e}}$ & \multicolumn{2}{|c|}{1.93} & 1.86 \\
\hline
\end{tabular}

${ }^{a}$ All transition energies calculated using the cc-pVDZ basis set, PCM, and geometries optimized at the B3LYP-PCM/SVP level of theory. Oscillator strengths in parentheses. HOMO $\rightarrow$ LUMO CI expansion coefficients are given in Table S7 of the SD.

${ }^{\mathrm{b}}$ Emission data for the $5 \mathrm{Ea} 15 \mathrm{Ea}$ chromophore obtained through extrapolation procedure, as described in the Computational details section.

${ }^{\mathrm{c}} \mathrm{SS}$ solvation not implemented for LC- $\omega$ PBE in Gaussian 09.

${ }^{\mathrm{d}}$ Standard deviation.

${ }^{\mathrm{e}}$ Experimental value from Ref. [25]. 
Table 3

TD-DFT Q-band absorption and emission maxima of the $5 Z s 15 Z a$ and $15 Z a$ chromophores (in eV). ${ }^{\mathrm{a}}$

\begin{tabular}{|c|c|c|c|c|}
\hline \multirow[b]{3}{*}{ Chromophore } & \multirow[b]{3}{*}{ Functional } & \multicolumn{2}{|c|}{ Absorption } & \multirow{3}{*}{$\begin{array}{c}\frac{\text { Emission }}{\text { SS EQ solvation }} \\
\Delta E\left(\mathrm{~S}_{1} \rightarrow \mathrm{S}_{0}\right)\end{array}$} \\
\hline & & LR NEQ solvation & SS NEQ solvation & \\
\hline & & $\Delta E\left(\mathrm{~S}_{0} \rightarrow \mathrm{S}_{1}\right)$ & $\Delta E\left(\mathrm{~S}_{0} \rightarrow \mathrm{S}_{1}\right)$ & \\
\hline \multirow[t]{15}{*}{$5 Z s 15 Z a$} & BP86 & $1.79(1.32)$ & $1.93(1.09)$ & $1.82(1.05)$ \\
\hline & BLYP & $1.78(1.32)$ & $1.93(1.11)$ & $1.81(1.07)$ \\
\hline & PBE & $1.79(1.32)$ & $1.93(1.09)$ & $1.82(1.05)$ \\
\hline & $\tau$-HCTH & $1.80(1.35)$ & $1.94(1.14)$ & $1.82(1.08)$ \\
\hline & BHHLYP & $2.06(1.60)$ & $2.23(1.49)$ & $2.00(1.36)$ \\
\hline & B3LYP & $1.92(1.47)$ & $2.08(1.34)$ & $1.91(1.25)$ \\
\hline & PBE0 & $1.95(1.50)$ & $2.11(1.38)$ & $1.93(1.28)$ \\
\hline & M06-2X & $2.02(1.53)$ & $2.19(1.42)$ & $1.97(1.30)$ \\
\hline & M06-HF & $2.09(1.55)$ & $2.26(1.44)$ & $1.99(1.31)$ \\
\hline & LC-BLYP & $2.09(1.60)$ & $2.27(1.49)$ & $1.99(1.36)$ \\
\hline & $L C-\omega P B E^{b}$ & $2.08(1.58)$ & - & - \\
\hline & CAM-B3LYP & $2.03(1.54)$ & $2.19(1.43)$ & $1.96(1.31)$ \\
\hline & $\omega B 97 X-D$ & $2.04(1.55)$ & $2.21(1.44)$ & $1.97(1.31)$ \\
\hline & $\sigma$ (functional $^{\mathrm{c}}$ & 0.13 & 0.14 & 0.08 \\
\hline & $\operatorname{Exp}^{d}$ & \multicolumn{2}{|c|}{1.76} & - \\
\hline \multirow[t]{15}{*}{$15 Z a$} & BP86 & $1.81(1.20)$ & $1.96(1.02)$ & $1.81(0.84)$ \\
\hline & BLYP & $1.80(1.19)$ & $1.95(1.02)$ & $1.80(0.84)$ \\
\hline & PBE & $1.81(1.19)$ & $1.96(1.01)$ & $1.81(0.84)$ \\
\hline & $\tau$-НCТН & $1.81(1.21)$ & $1.97(1.06)$ & $1.82(0.87)$ \\
\hline & BHHLYP & $2.07(1.43)$ & $2.25(1.34)$ & $2.00(1.12)$ \\
\hline & B3LYP & $1.93(1.31)$ & $2.09(1.21)$ & $1.90(1.02)$ \\
\hline & PBE0 & $1.96(1.34)$ & $2.13(1.24)$ & $1.93(1.05)$ \\
\hline & M06-2X & $2.04(1.38)$ & $2.21(1.29)$ & $1.97(1.08)$ \\
\hline & M06-HF & $2.11(1.41)$ & $2.28(1.32)$ & $2.00(1.11)$ \\
\hline & LC-BLYP & $2.10(1.44)$ & $2.28(1.36)$ & $2.00(1.14)$ \\
\hline & $\mathrm{LC}-\omega \mathrm{PBE} \mathrm{b}^{\mathrm{b}}$ & $2.09(1.43)$ & - & - \\
\hline & CAM-B3LYP & $2.04(1.39)$ & $2.21(1.30)$ & $1.97(1.09)$ \\
\hline & $\omega B 97 X-D$ & $2.05(1.39)$ & $2.22(1.30)$ & $1.97(1.10)$ \\
\hline & $\sigma(\text { functional })^{\mathrm{c}}$ & 0.12 & 0.13 & 0.08 \\
\hline & $\operatorname{Exp}^{d}$ & \multicolumn{2}{|c|}{1.83} & - \\
\hline
\end{tabular}

${ }^{a}$ All transition energies calculated using the cc-pVDZ basis set, PCM, and geometries optimized at the B3LYP-PCM/SVP level of theory. Oscillator strengths in parentheses. HOMO $\rightarrow$ LUMO CI expansion coefficients are given in Table S8 of the SD.

${ }^{\mathrm{b}} \mathrm{SS}$ solvation not implemented for LC- $\omega$ PBE in Gaussian 09.

${ }^{\mathrm{c}}$ Standard deviation.

${ }^{\mathrm{d}}$ Experimental value from Ref. [25]. 
Table 4

CIS, CIS(D), CC2 and CASPT2 Q-band absorption and emission maxima (in eV). ${ }^{\text {a }}$

\begin{tabular}{|c|c|c|c|c|}
\hline \multirow[b]{3}{*}{ Chromophore } & \multirow[b]{3}{*}{ Method $^{\mathrm{c}}$} & \multicolumn{2}{|c|}{ Absorption } & \multirow{3}{*}{$\begin{array}{c}\frac{\text { Emission }^{\mathrm{b}}}{\mathrm{SS} \text { EQ solvation }} \\
\Delta E\left(\mathrm{~S}_{1} \rightarrow \mathrm{S}_{0}\right)\end{array}$} \\
\hline & & LR NEQ solvation & SS NEQ solvation & \\
\hline & & $\Delta E\left(\mathrm{~S}_{0} \rightarrow \mathrm{S}_{1}\right)$ & $\Delta E\left(\mathrm{~S}_{0} \rightarrow \mathrm{S}_{1}\right)$ & \\
\hline \multirow[t]{5}{*}{$5 Z a 15 E a$} & CIS & $2.31(2.24)$ & $2.75(2.53)$ & $2.47(2.58)$ \\
\hline & CIS(D) & $1.78(2.26)$ & $2.23(2.56)$ & $2.02(2.61)$ \\
\hline & $\mathrm{CC} 2$ & $1.73(1.94)$ & $2.18(2.24)$ & $2.00(2.33)$ \\
\hline & CASPT2 & $1.91(1.39)$ & $2.36(1.68)$ & $2.18(1.79)$ \\
\hline & $\operatorname{Exp}^{d}$ & \multicolumn{2}{|c|}{1.89} & 1.85 \\
\hline \multirow[t]{5}{*}{$5 E a 15 E a$} & CIS & $2.35(2.20)$ & $2.79(2.49)$ & 2.55 \\
\hline & CIS(D) & $1.83(2.24)$ & $2.27(2.53)$ & 2.07 \\
\hline & $\mathrm{CC} 2$ & $1.78(1.91)$ & $2.22(2.20)$ & 2.05 \\
\hline & CASPT2 & $2.00(1.63)$ & $2.43(1.92)$ & 2.16 \\
\hline & $\operatorname{Exp}^{d}$ & \multicolumn{2}{|c|}{1.93} & 1.86 \\
\hline \multirow[t]{5}{*}{$5 Z s 15 Z a$} & CIS & $2.23(1.66)$ & $2.63(1.79)$ & $2.31(1.66)$ \\
\hline & CIS(D) & $1.73(1.66)$ & $2.14(1.79)$ & $1.91(1.66)$ \\
\hline & $\mathrm{CC} 2$ & $1.68(1.46)$ & $2.08(1.59)$ & $1.88(1.50)$ \\
\hline & CASPT2 & $1.86(1.38)$ & $2.26(1.51)$ & $-{ }^{\mathrm{e}}$ \\
\hline & $\operatorname{Exp}^{\mathrm{d}}$ & \multicolumn{2}{|c|}{1.76} & - \\
\hline \multirow[t]{5}{*}{$15 Z a$} & CIS & $2.23(1.49)$ & $2.63(1.61)$ & $2.31(1.38)$ \\
\hline & CIS(D) & $1.75(1.49)$ & $2.15(1.61)$ & $1.92(1.38)$ \\
\hline & $\mathrm{CC} 2$ & $1.70(1.34)$ & $2.11(1.40)$ & $1.89(1.27)$ \\
\hline & CASPT2 & $1.95(1.56)$ & $2.36(1.68)$ & $2.05(1.07)$ \\
\hline & $\operatorname{Exp}^{d}$ & \multicolumn{2}{|c|}{1.83} & - \\
\hline
\end{tabular}

${ }^{a}$ All transition energies calculated using the cc-pVDZ basis set, PCM, and geometries optimized at the B3LYP-PCM/SVP level of theory. Oscillator strengths in parentheses. HOMO $\rightarrow$ LUMO CI expansion coefficients from the CIS and CC2 calculations are given in Tables S7 and S8 of the SD. Details of the CASSCF wavefunctions underlying the CASPT2 calculations are given in Table S9 of the SD.

${ }^{\mathrm{b}}$ Emission data for the 5Ea15Ea chromophore obtained through extrapolation procedure, as described in the Computational details section.

${ }^{\mathrm{c}}$ CIS(D), CC2 and CASPT2 gas-phase calculations with a posteriori solvent corrections computed using CIS.

${ }^{\mathrm{d}}$ Experimental value from Ref. [25].

${ }^{\mathrm{e}}$ No reliable estimate obtained because of substantially different reference weights in the CASPT2

$\mathrm{S}_{0}$ and $\mathrm{S}_{1}$ calculations. 


\section{Table 5}

TD-DFT Q-band absorption and emission maxima of the 5Za15Ea chromophore at B3LYP and non-B3LYP geometries (in $\mathrm{eV}){ }^{\mathrm{a}}$

\begin{tabular}{|c|c|c|c|c|c|c|}
\hline \multirow[b]{4}{*}{ Functional } & \multicolumn{4}{|c|}{ Absorption } & \multirow{2}{*}{\multicolumn{2}{|c|}{$\begin{array}{c}\text { Emission } \\
\text { SS EQ solvation } \\
\end{array}$}} \\
\hline & \multicolumn{2}{|c|}{ LR NEQ solvation } & \multicolumn{2}{|c|}{ SS NEQ solvation } & & \\
\hline & $\begin{array}{c}\text { Geometry: } \\
\text { B3LYP }\end{array}$ & $\begin{array}{l}\text { Geometry: } \\
\text { Functional }\end{array}$ & $\begin{array}{l}\text { Geometry: } \\
\text { B3LYP }\end{array}$ & $\begin{array}{l}\text { Geometry: } \\
\text { Functional }\end{array}$ & $\begin{array}{c}\text { Geometry: } \\
\text { B3LYP }\end{array}$ & $\begin{array}{l}\text { Geometry: } \\
\text { Functional }\end{array}$ \\
\hline & $\Delta E\left(\mathrm{~S}_{0} \rightarrow \mathrm{S}_{1}\right)$ & $\Delta E\left(\mathrm{~S}_{0} \rightarrow \mathrm{S}_{1}\right)$ & $\Delta E\left(\mathrm{~S}_{0} \rightarrow \mathrm{S}_{1}\right)$ & $\Delta E\left(\mathrm{~S}_{0} \rightarrow \mathrm{S}_{1}\right)$ & $\Delta E\left(\mathrm{~S}_{1} \rightarrow \mathrm{S}_{0}\right)$ & $\Delta E\left(\mathrm{~S}_{1} \rightarrow \mathrm{S}_{0}\right)$ \\
\hline BP86 & $1.89(1.87)$ & $1.83(1.89)$ & $2.05(1.66)$ & $2.00(1.68)$ & $1.96(1.75)$ & $1.93(1.71)$ \\
\hline BLYP & $1.88(1.86)$ & $1.82(1.88)$ & $2.05(1.66)$ & $1.99(1.68)$ & $1.95(1.75)$ & $1.91(1.71)$ \\
\hline PBE & $1.89(1.86)$ & $1.83(1.89)$ & $2.05(1.65)$ & $2.00(1.68)$ & $1.96(1.74)$ & $1.93(1.71)$ \\
\hline$\tau$-НCТН & $1.89(1.89)$ & $1.86(1.92)$ & $2.06(1.70)$ & $2.03(1.73)$ & $1.97(1.78)$ & $1.96(1.77)$ \\
\hline BHHLYP & $2.17(2.25)$ & $2.29(2.23)$ & $2.36(2.12)$ & $2.47(2.11)$ & $2.15(2.13)$ & $2.20(2.14)$ \\
\hline B3LYP & $2.01(2.05)$ & $2.01(2.05)$ & $2.19(1.91)$ & $2.19(1.91)$ & $2.05(1.94)$ & $2.05(1.94)$ \\
\hline PBE0 & $2.05(2.10)$ & $2.07(2.11)$ & $2.23(1.96)$ & $2.25(1.96)$ & $2.07(1.99)$ & $2.09(2.00)$ \\
\hline M06-2X & $2.12(2.15)$ & $2.21(2.13)$ & $2.31(2.02)$ & $2.39(2.00)$ & $2.11(2.04)$ & $2.12(1.92)$ \\
\hline M06-HF & $2.19(2.18)$ & $2.42(2.15)$ & $2.38(2.06)$ & $2.60(2.04)$ & $2.13(2.08)$ & $2.20(1.93)$ \\
\hline LC-BLYP & $2.19(2.23)$ & $2.41(2.19)$ & $2.39(2.12)$ & $2.59(2.08)$ & $2.14(2.14)$ & $2.25(2.12)$ \\
\hline CAM-B3LYP & $2.13(2.17)$ & $2.23(2.15)$ & $2.31(2.04)$ & $2.41(2.02)$ & $2.11(2.06)$ & $2.15(2.05)$ \\
\hline$\omega B 97 X-D$ & $2.14(2.18)$ & $2.26(2.14)$ & $2.33(2.05)$ & $2.44(2.01)$ & $2.11(2.06)$ & $2.15(2.04)$ \\
\hline 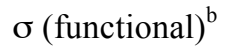 & 0.13 & 0.23 & 0.14 & 0.23 & 0.08 & 0.12 \\
\hline $\operatorname{Exp}^{\mathrm{c}}$ & & & & & & \\
\hline
\end{tabular}

${ }^{a}$ All transition energies calculated using the cc-pVDZ basis set, PCM, and geometries optimized with either B3LYP or the functional used to calculate transition energies in combination with the SVP basis set and PCM. Oscillator strengths in parentheses.

${ }^{\mathrm{b}}$ Standard deviation.

${ }^{\mathrm{c}}$ Experimental value from Ref. [25]. 


\section{Table 6}

Gas-phase Q-band absorption maxima $(\Delta E)$ and solvatochromic shifts relative to the gas phase $(\Delta \Delta E)$ calculated with different methods (in eV). ${ }^{\mathrm{a}}$

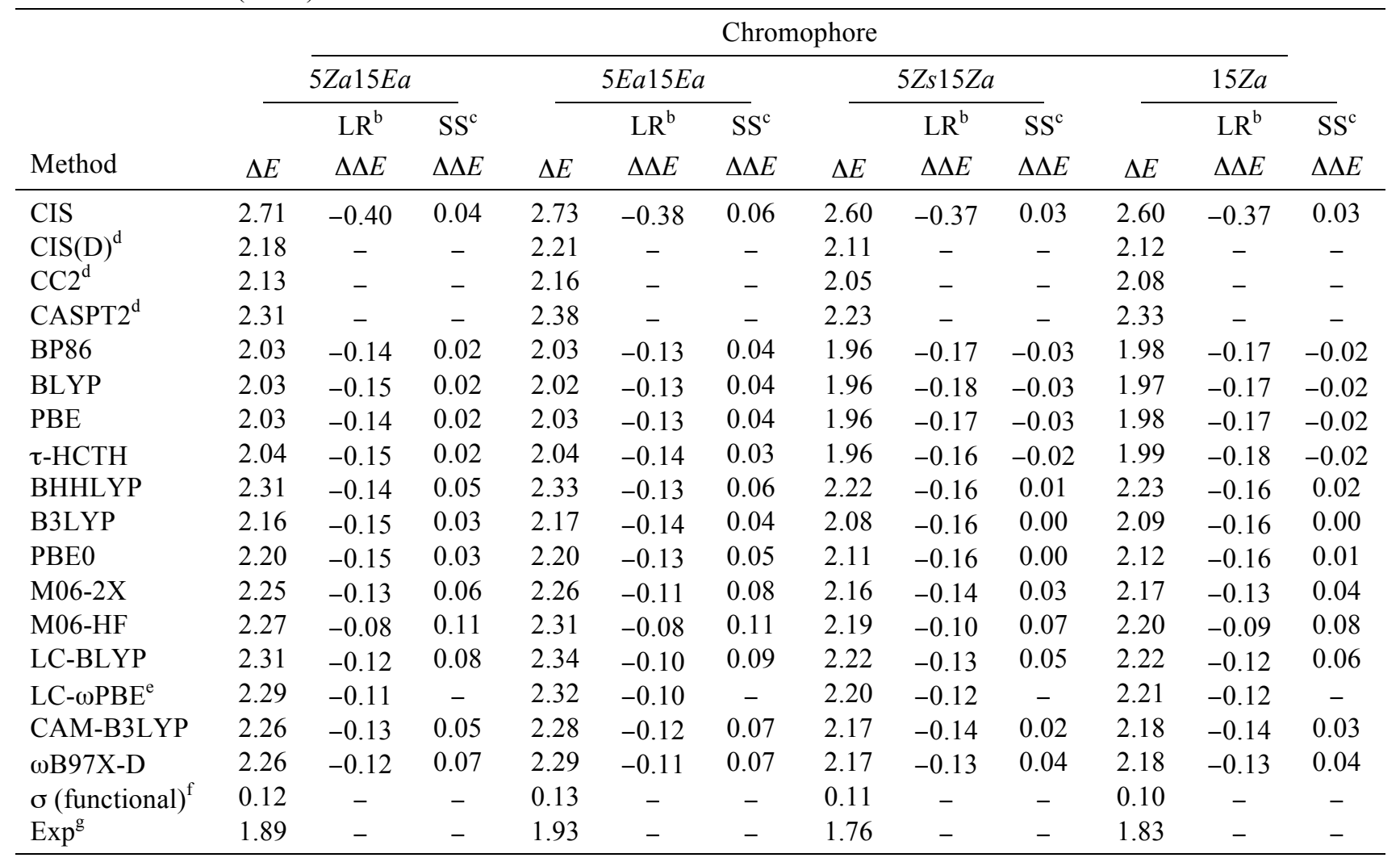

${ }^{a}$ All absorption maxima and solvatochromic shifts calculated using the cc-pVDZ basis set and geometries optimized at the B3LYP-PCM/SVP level of theory.

${ }^{\mathrm{b}}$ Solvatochromic shift calculated using LR NEQ solvation.

${ }^{\mathrm{c}}$ Solvatochromic shift calculated using SS NEQ solvation.

${ }^{\mathrm{d}}$ Solvation calculations not performed with CIS(D), CC2 and CASPT2.

${ }^{\mathrm{e}} \mathrm{SS}$ solvation not implemented for LC- $\omega \mathrm{PBE}$ in Gaussian 09.

${ }^{\mathrm{f}}$ Standard deviation considering DFT methods only.

${ }^{\mathrm{g}}$ Experimental value from Ref. [25]. 


\section{Figure captions}

Fig. 1. Structures of the BV chromophore and the locked $15 Z a$ bilin chromophore containing a cyclic lock between pyrrole rings $\mathrm{C}$ and $\mathrm{D}\left(\mathrm{R}=\mathrm{CH}_{2} \mathrm{CH}_{2} \mathrm{COOH}\right)$.

Fig. 2. Structures of the locked bilin chromophores considered in this work $(\mathrm{R}=$ $\left.\mathrm{CH}_{2} \mathrm{CH}_{2} \mathrm{COOH}\right)$.

Fig. 3. Structures of the chromophore-water complexes considered. 

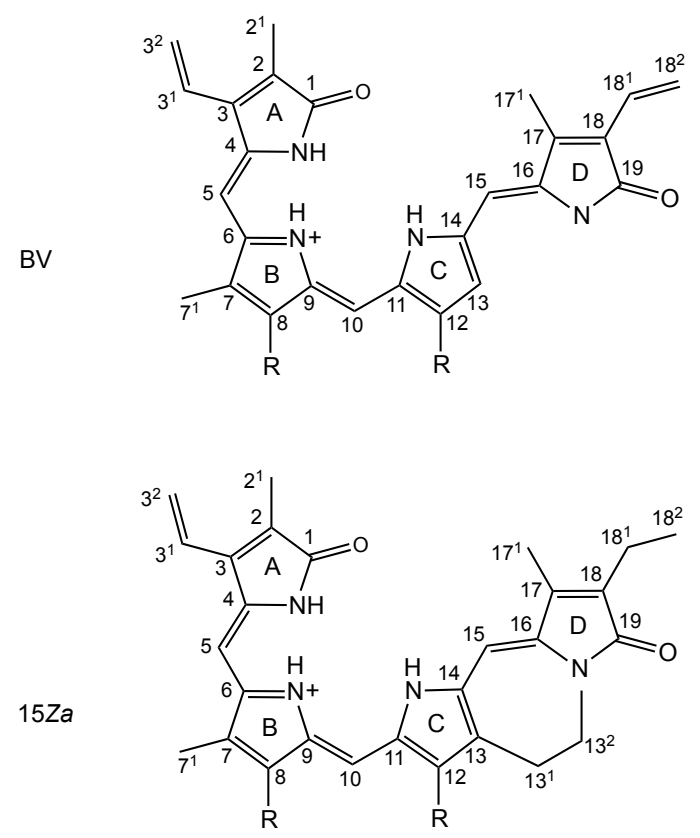

Fig. 1 

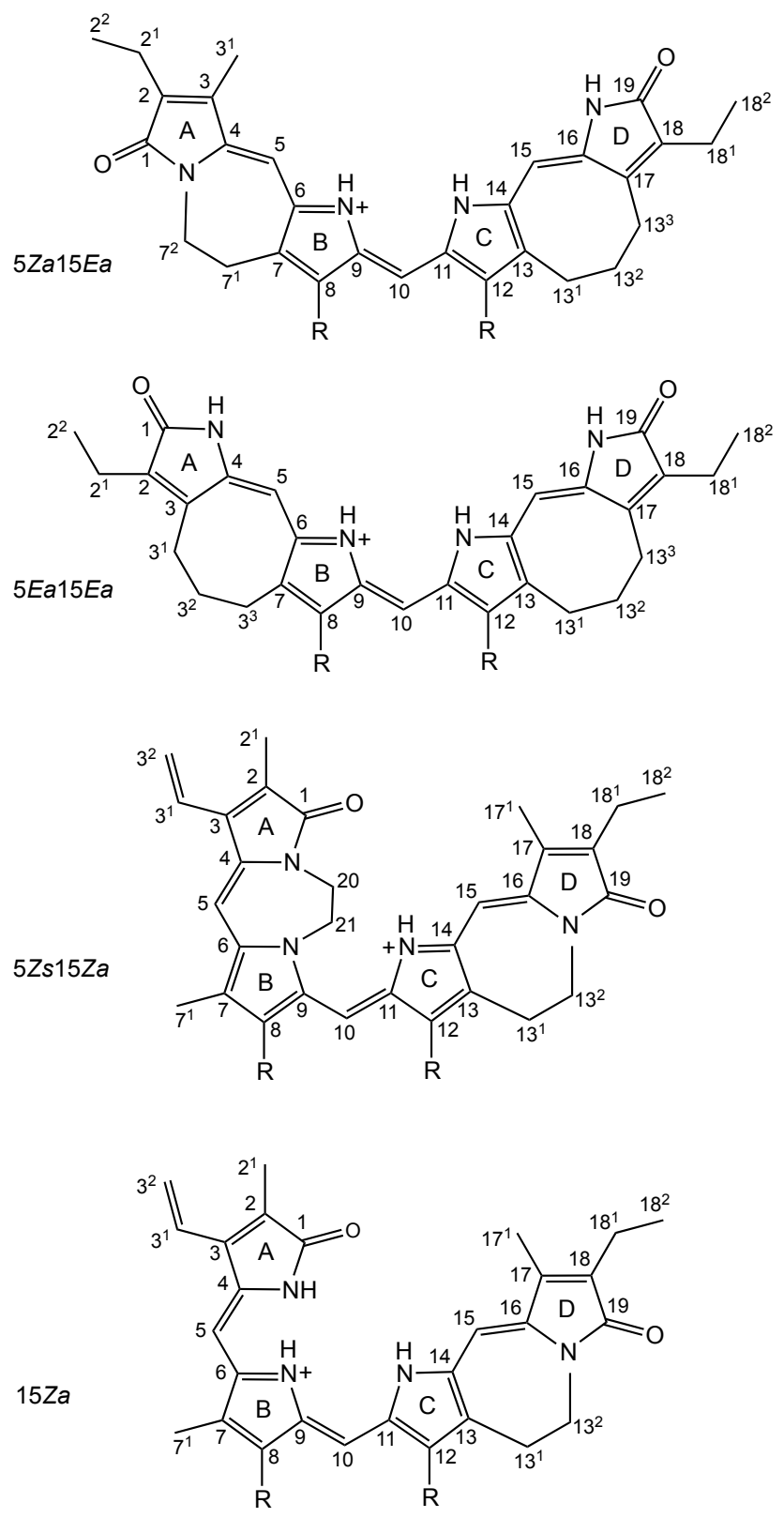

Fig. 2 

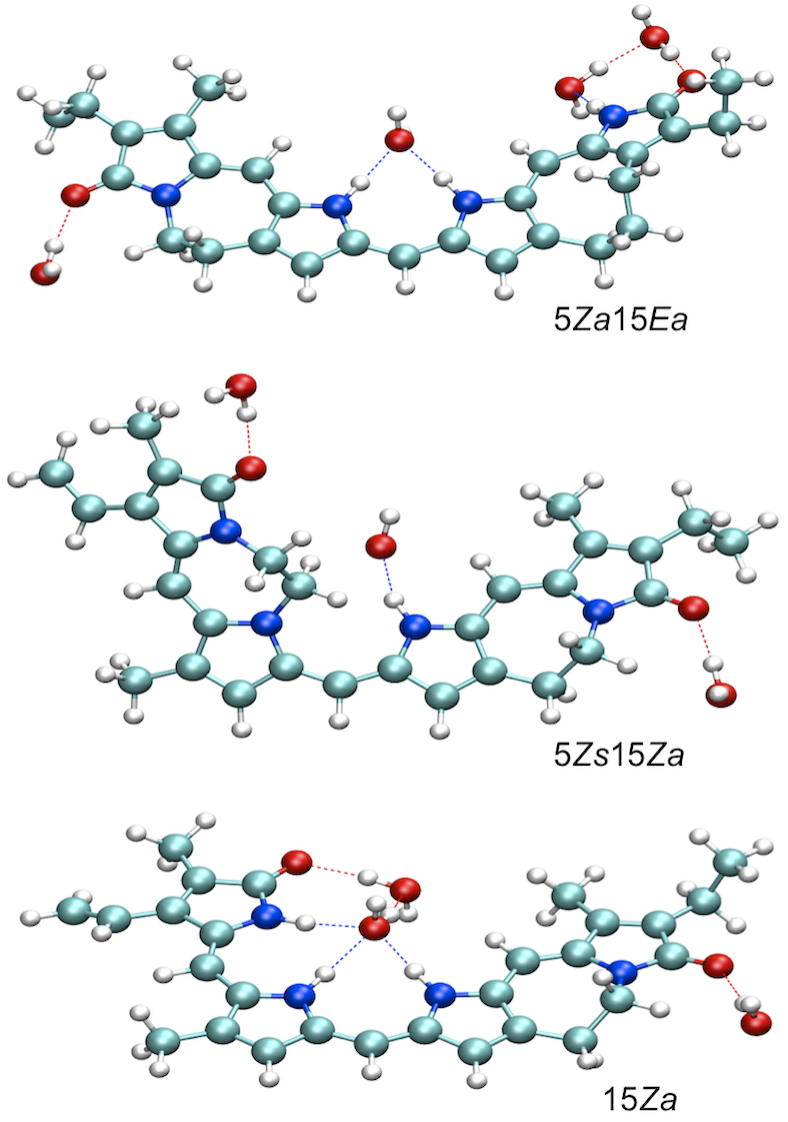

Fig. 3 